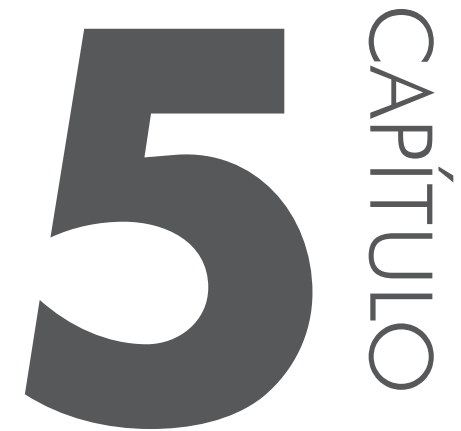

\title{
O limiar da política HABITACIONAL NO BRASIL: DO IMPÉRIO À REPÚBLICA VELHA
}

Bruno Lourenço Siqueira Magda Valéria Silva

Resumo: O objetivo do artigo é analisar o início das políticas habitacionais no Brasil, com ênfase no período correspondente entre o Império e a República Velha. Os procedimentos metodológicos se pautaram pela pesquisa documental e bibliográfica cuja temática versa sobre as ações do Estado brasileiro quanto ao enfrentamento da questão da habitação popular. A literatura analisada apresenta o modo pontual e sem compromisso que o Estado teve com a produção de moradias populares entre o século XIX e início do século XX. O paradigma liberal hegemônico, à época, descartava a participação mais incisiva do Estado na provisão de habitações populares. Contudo, as poucas ações estatais foram para estimular a produção de moradias por iniciativa privada e regulamentar o uso e a ocupação 
do solo urbano. Tais procedimentos ante a tutela estatal produziram dois processos perversos socialmente e que se combinam ao mesmo tempo: a gentrificação e a expansão horizontal da cidade.

Palavras-chave: Habitação. Estado. Políticas.

Abstract: The goal of the present paper is to analyze the beginning of housing policies in Brazil highlighting the period from the Empire of Brazil (Império) and the Old Republic (República Velha). The methodological procedures were based on documentary and bibliographical research on actions taken by the Brazilian State concerning on how to cope with affordable housing. The analyzed literature presents the State uncommited manner as to the construction of affordable housing from the 19 th century to the beginning of the 20th century. The hegemony of the liberal paradigm at the time dismissed a more effective State participation in providing affordable housing. The few State actions were, however, to encourage the construction of housing by the private sector and to regulate the use and occupation of urban land. These procedures under the state tutelage produced two socially deviant processes that agree simultaneously such as the gentrification and the horizontal expansion of the city.

Keywords: Housing. State. Formatting. Housing policies.

\section{INTRODUC̣ÃO}

A política habitacional brasileira tem sido foco de análises e debates nos mais diversos segmentos da sociedade, dentre estes, se destacam: pesquisadores, jornalistas, empresários e acadêmicos.

Contudo, analisar a conjuntura atual sem compreender o processo histórico das políticas habitacionais do país não permite desvendar os reais interesses e beneficiados do presente.

O resgate histórico das intervenções estatais no plano da habitação popular se torna relevante, pois, assim é possível avaliar os avanços e retrocessos de tais políticas voltadas para atender parte numerosa da população brasileira, e ainda, conceber as origens de inúmeros problemas urbanos contemporâneos ligados ao modo estatal de interposição da questão da moradia popular.

Desse modo, o presente artigo tem o objetivo de analisar as origens da política de habitação popular, sobretudo com interesse temporal circunscrito ao período Imperial (1822-1889) e à República Velha (1889-1930).

Os procedimentos metodológicos se pautaram pela pesquisa documental (decretos e leis) e pela pesquisa bibliográfica que destacam a questão habitacional no período proposto 


\subsection{O papel do Estado e a política urbana no Brasil}

A origem das cidades no Brasil não é resultado apenas dos processos de industrialização e de urbanização que aconteceram ao longo do século XX. As primeiras cidades no Brasil estavam intimamente ligadas ao seu meio geográfico, cuja função era facilitar a ocupação efetiva e possibilitar a expansão da colonização nos mais diversos pontos do território sob domínio português.

O fim do sistema colonial estabelece uma nova forma de organização do espaço, seja pelo novo arranjo político-institucional que a República exige, seja pelo arranjo econômico-demográfico com base na centralidade cafeeira. A cidade torna-se, cada vez mais, a referência das decisões políticas, ao passo que a fazenda ainda é a base da economia nacional (MOREIRA, 2011, p. 79).

As consequências oriundas da mudança do modelo agroexportador para o modelo urbano-industrial foram as mais diversas possíveis no país, perpassando todos os setores, tais como: social, econômico, político, cultural e outros.

Todavia, cabe destacar que a organização e estrutura da sociedade brasileira, inserida no sistema capitalista, apresentam como características o desenvolvimento desigual das estruturas econômicas, as relações sociais pautadas pela luta de classes devido aos interesses antagônicos e divergentes, e ainda, a segregação socioespacial como produto e meio de produção para novas contradições no espaço urbano.

O Estado, portanto, dentro desse contexto histórico é paradoxalmente produtor de desigualdades e, ao mesmo tempo, responsável também por amenizar e/ ou por neutralizar o desenvolvimento desigual das estruturas sociais a partir de políticas intervencionistas.

Contudo, o ideal de que o Estado como sociedade política deve atuar para intermediar os conflitos existentes dentro da organização social produz inexoravelmente efeitos contraditórios. Em outras palavras, as diferentes concepções de bem comum estão intimamente relacionadas à condição social, política e econômica. Dentro do sistema capitalista, a concepção de bem comum é relativizada pela ideologia dominante. De modo geral, o bem comum passa a ser entendido como um processo que assegura os interesses privados de uma minoria social e econômica em detrimento dos interesses coletivos.

E é justamente por essa complexidade de enfoques que o estudo sobre a habitação torna-se relevante e, ao mesmo tempo, um desafio para a apreensão da realidade socioespacial da cidade capitalista.

Vide o contexto urbano da (re)produção capitalista, a habitação é indispensável para a reprodução da força de trabalho, pois, é o espaço para a reprodução da vida, individual e familiar, lugar privilegiado para a produção dos 
valores de uso e do consumo. Mas, é também um bem permutável por outro de valor equivalente, é valor de troca e, nesse sentido, além de um produto, é uma mercadoria (VÉRAS; BONDUKI, 1986). Uma mercadoria, cuja produção e consumo adquirem aspectos sociais amplos que vão desde o atendimento às necessidades básicas do indivíduo (abrigo) ao consumo dos signos (sociais) e valores associados à ela.

Diante de uma racionalidade limitada (lógica produzida pelo mundo da mercadoria, do dinheiro e do valor de troca), a sociedade urbana passa a se expressar diante da forma urbana, que, por sua vez, irá limitar a "[...] simultaneidade e os encontros à forma dos trocadores, e o lugar de encontro onde se conclui o contrato ou quase-contrato de troca equivalente: o reduz ao mercado." (LEFEBVRE, 2001, p. 87).

Destarte, enquanto mercadoria, a habitação é um bem caro, cuja representação monetária em geral se eleva com o tempo. Portanto, é um produto que, ante certas condições (física-estrutural, localização etc.), não se deprecia, uma vez adquirido e utilizado, pelo contrário, torna-se investimento.

Não obstante, o discurso construído por intenções ideológicas conservadoras em torno da "conquista da casa própria" limitou-se à função de abrigar, desvinculada dos equipamentos e serviços urbanos, que, por sua vez, criam as condições mínimas para alcançar a cidadania (VÉRAS; BONDUKI, 1986).

Submetida a essa lógica, a cidade produz e é produzida pela desigualdade de classes, proliferando áreas segregadas e acentuando a espoliação urbana. Em seguida, a crise que se anuncia é a crise urbana, sendo a crise da habitação apenas uma parte.

\subsection{O limiar da política habitacional social no Brasil}

Sob a égide do liberalismo econômico, especificamente o período que corresponde ao fim do sistema monárquico e ao início da Primeira República (18891930), verificam-se ações estatais pontuais no âmbito habitacional.

As ações do Governo Imperial no plano habitacional visavam, em grande medida, combater na cidade do Rio de Janeiro as habitações coletivas (casas de cômodos, estalagem, hospedarias etc.), comumente denominadas de cortiços (ABREU, 2003; OLIVEIRA, 2009).

O discurso oficial sobre o combate aos cortiços se centrava na questão da saúde pública. Epidemias de cólera, de varíola e de febre amarela assolavam periodicamente a cidade em meados do século XIX (ABREU, 2003). Todavia, cabe destacar a relevância da localização central que os cortiços ocupavam enquanto condição indispensável para a sobrevivência de uma parcela considerável da po- 
pulação, pois, para os trabalhadores livres e escravos de ganho ${ }^{1}$, o trabalho deveria ser procurado diariamente (ABREU, 2003).

A intervenção do Estado no plano habitacional iniciou-se em 1853 com a edição da Lei $\mathrm{n}^{\circ} 719$ que concedia privilégios à empresa privada para construir casas operárias e higiênicas (OLIVEIRA, 2009). Mas, de fato, os estímulos mais contundentes aconteceram com o Decreto $\mathrm{n}^{\circ} 2.686$, de outubro de 1875 , e com a Lei $\mathrm{n}^{\circ} 3.151$, de dezembro de 1882.

O primeiro preconizava a isenção absoluta da Décima Urbana ${ }^{2}$ por até 10 anos para aquelas empresas que construíssem, nos arrabaldes da cidade do Rio de Janeiro, grandes edifícios, denominados "Evonias", "para dar commodo agasalho às famílias pobres e aos artistas” (BRASIL, 2015a).

O segundo amplia os incentivos para "as empresas que se organizarem com o fim de construir edifícios destinados à habitação de operários e classes pobres" (BRASIL, 2015b), tais como: a ampliação da isenção por até 20 anos do imposto predial, a dispensa do imposto de transmissão quanto à aquisição de imóveis necessários às construções e o direito à desapropriação dos terrenos particulares.

Ambos os instrumentos legais supracitados evidenciaram que a localização das construções das habitações para os operários se dariam nos arrabaldes da cidade, ou seja, nos arredores, no subúrbio. Para que as leis fossem editadas, o argumento principal era de cunho higienista ${ }^{3}$, com vistas à saúde pública, todavia, paralelo ao discurso oficial, outro processo chama a atenção, a gentrificação ${ }^{4}$, com o estímulo estatal.

Mesmo que essas leis não tenham alcançado bons resultados, conforme descreveram Abreu (2003) e Oliveira (2009), há uma nítida intenção por parte do governo de modificar o perfil social da área central da capital federal.

1 O escravo de ganho possuía permissão de seu proprietário para realizar algumas tarefas e ficar com uma parte do dinheiro. As atividades mais comuns desses escravos eram o transporte de cargas e pessoas, vender alguns produtos como café torrado e doces, tomar conta de estabelecimento comercial e realizar pequenos reparos.

2 A Décima Urbana foi o imposto, com pagamento anual à Real Fazenda, criado em 1808, o qual consistia na cobrança de $10 \%$ do rendimento líquido dos prédios urbanos em condições habitáveis dentro dos limites das cidades e vilas. BRASIL. Leis etc. Colecção das Leis do Brazil de 1808. Rio de Janeiro: Imprensa Nacional, 1891. p. 69-73. Disponível em: ‘http://bd.camara.gov. br/bd/bitstream/handle/bdcamara/18319/colleccao_leis_1808_parte1.pdf? sequence=4 . Acesso: 15 mar. 2016.

3 Sobre a crise e a superação do pensamento higienista pelo sanitarista ver: ABREU, M. de A. Cidade brasileira - 1870-1930. In: SPÓSITO, M. E. B. (Org.). Urbanização e cidades: perspectivas geográficas. Presidente Prudente: UNESP, p. 35-44, 2001.

4 Ver mais em: SMITH, N. Gentrificação, a fronteira e a reestruturação do espaço urbano. IN: GEOUSP - Espaço e Tempo, São Paulo, Departamento de Geografia, FFLCH, USP, n. 21, p. 15$31,2007$. 
O período entre a abolição da escravatura (1888) e o da Revolução de 1930 é caracterizado por importantes transformações econômicas, sociais e políticas no país. O processo de desenvolvimento mediante substituição de importações, com a formação de um parque industrial de bens de consumo não duráveis (tecido, roupas, alimentos), principalmente no Rio de Janeiro e em São Paulo, estimula ainda mais o processo de urbanização (SINGER, 1973).

Contudo, o modelo agroexportador ainda se constituía a base da organização socioeconômica do Brasil. É nesse contexto que Moreira (2011) esclarece que o processo de formação da sociedade do trabalho no país destaca a interface entre a fazenda (campo) e a cidade, sendo a fábrica o elo entre esses espaços. Para o autor: "O todo de que a fazenda e cidade são bases e elos orgânicos. E cuja lógica é o que define o que é a fazenda e o que é a cidade. E, assim, o que será a indústria nascente" (MOREIRA, 2011, p. 111).

O modo que prevalece durante a República Velha no que tange à produção de moradias é similar ao do período Imperial, ou seja, o governo não produz, mas estimula o capital privado a investir no ramo da construção. Esse estímulo acontece de duas formas: a) a não intervenção do Estado nos preços dos aluguéis torna a produção de casas com esta finalidade uma forma segura e excelente de rentabilizar poupanças e recursos disponíveis na economia urbana; b) à emergência do processo de industrialização, os incentivos do poder público para a construção de vilas operárias.

No que tange à primeira forma, o próprio cenário econômico brasileiro nos primeiros anos da República era favorável à produção de moradias para aluguel, também conhecida como produção rentista (BONDUKI, 2011).

Segundo Prado Júnior (1998), são os fatores externos e internos que explicam o apogeu da economia produtora de matérias-primas e gêneros tropicais no Brasil entre os anos finais do século XIX e os do início do século XX. Os externos estão relacionados ao desenvolvimento do comércio internacional advindos com o progresso das técnicas de produção industrial e dos sistemas de transportes. A conjuntura interna, por sua vez, permitiu avanços econômicos, principalmente em consequência da resolução do problema da mão de obra, tanto com a abolição da escravidão quanto com os estímulos à imigração europeia.

Todavia, outro efeito do afluxo de imigrantes nas duas principais praças comerciais do Brasil, as cidades do Rio de Janeiro e de São Paulo, foi a elevação da procura por moradia de aluguel. A valorização imobiliária se constituía, assim, em uma "importante opção de investimento para reserva de valor, na ausência de um mercado de capitais” (BONDUKI, 1994, p.712).

Outro fato político-econômico que dinamizou o mercado de terras tem origem na última década do século XIX, durante a qual o país passou por uma grave 
crise financeira, denominada de Encilhamento ${ }^{5}$, cuja origem remonta a falta de meio circulante suficiente para atender as necessidades crescentes dos negócios num ambiente econômico especulativo (PRADO JÚNIOR, 1998). A crise conduziu os capitais para o setor imobiliário "[...] seja na forma de compra de terra para estoque de reserva de valores, seja na forma de construção de moradias para aluguel, alternativas que passam a ser percebidas como mais seguras" (RIBEIRO, 1991 apud OLIVEIRA, 2009, p. 25).

A título de exemplo, Bonduki (1994, p. 713) informa que em São Paulo, em 1920, “[...] apenas 19\% dos prédios eram habitados por seus proprietários, predominando largamente o aluguel como forma básica de acesso à moradia.” A inexistência de qualquer forma de financiamento para a aquisição da própria moradia levou quase a totalidade dos trabalhadores à condição de inquilino, e ainda, geralmente, em cortiços ocupados por mais de uma família (BONDUKI, 1994).

A segunda forma de estímulo estatal para a construção de moradias para os trabalhadores se deu a partir da constituição das vilas operárias na emergência da indústria moderna, sobretudo, após a segunda metade do século XIX. A difusão dessa prática de construção de moradias por parte das empresas para os seus operários aconteceu tanto nas cidades quanto no campo, mas invariavelmente os operários estavam ligados à indústria (têxtil, papel, cimento etc.), às empresas de mineração, às empresas de geração de energia, às empresas companhias ferroviárias e outros poucos ramos da atividade econômica (CORREIA, 2006).

As vilas operárias eram "[...] conjuntos de casas construídas pelas indústrias para serem alugadas a baixos aluguéis ou mesmo oferecidas gratuitamente a seus operários. Estas iniciativas tiveram um impacto importante em várias cidades brasileiras, pois são os primeiros empreendimentos habitacionais de grande porte construídos no país” (BONDUKI, 1994, p. 715).

Conforme apresentado por Correia (2006), entre 1880 e 1930, as vilas operárias (ver Figura 1) disseminam-se em larga escala, em diferentes estados e regiões. É nesse contexto que as vilas operárias irão se afirmar “como uma importante expressão da era industrial não apenas por suas origens, usos, funções e conflitos sociais, como também por suas características formais, que usualmente remetem a valores, materiais e símbolos do mundo fabril" (CORREIA, 2006, p. 14).

As vilas operárias se diferenciam principalmente pelo tamanho e pela região industrial, mas em todas, as moradias estão nas adjacências da fábrica. A estru-

5 Crise econômica que abateu o Brasil nos anos de 1890 e 1891. A expressão encilhamento extraída do vocabulário dos hipódromos remetia à confusão das apostas, momentos antes da largada, enquanto os jóqueis encilhavam (arreavam) seus cavalos. Ver mais em: <http://desafios.ipea.gov. br/index.php? option=com_content\&view=article\&id=2490: catid=28\&Itemid=23>. Acesso em: 03 mar. 2015. 
tura da vila operária conta ainda com escola, farmácia, assistência médica, usina elétrica e algum espaço para lazer. Destes, a escola se destaca entre os equipamentos disponíveis à família dos trabalhadores, pois sua função vai além da alfabetização, objetiva-se com ela generalizar o modelo ideológico industrial, pautado na ordem e na disciplina (MOREIRA, 2011).

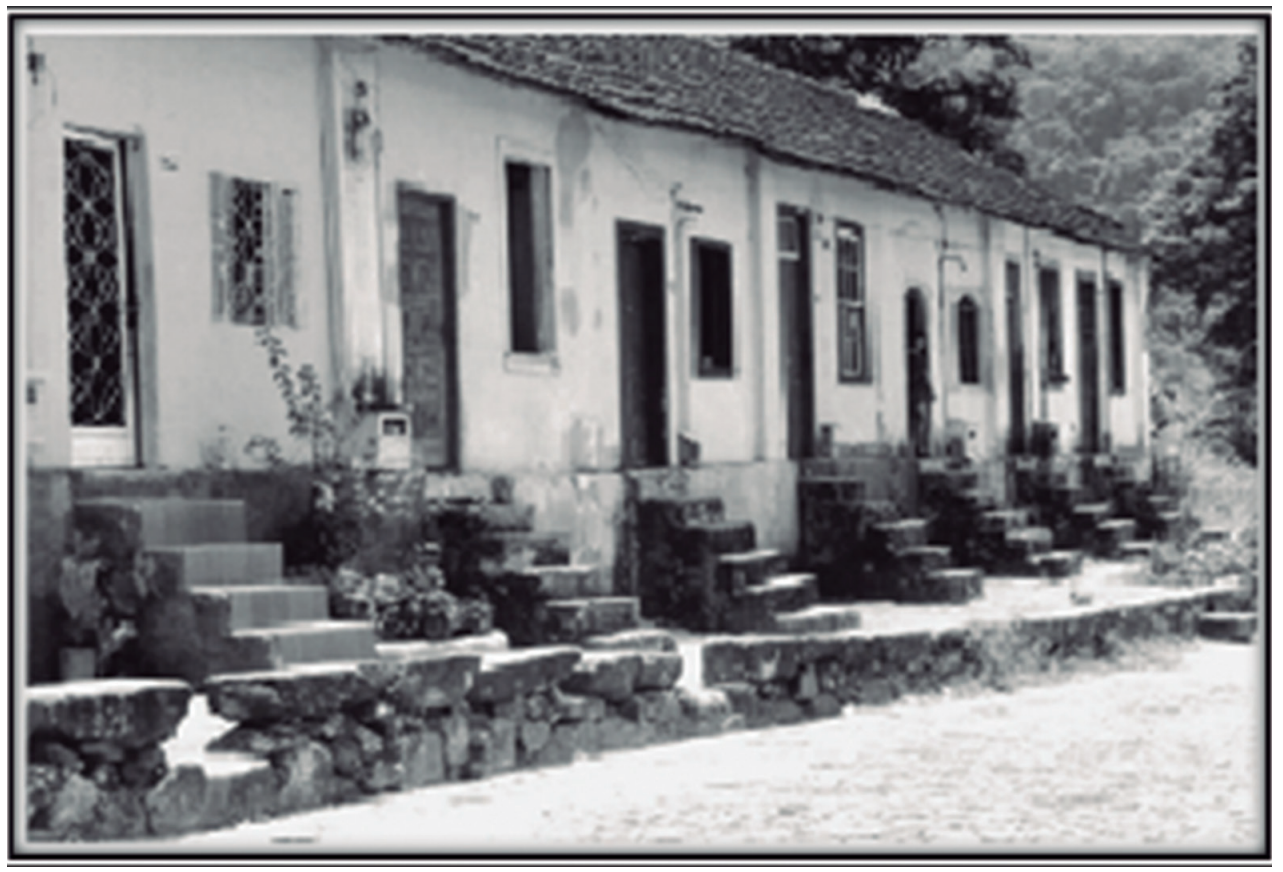

Figura 1. Vila operária erguida pela Companhia de Fiação Cometa, Petrópolis-RJ. Fonte: Correia (2006).

Para Moreira (2011), sob o comando da indústria, a divisão territorial do trabalho privilegiará a interação da fazenda ${ }^{6}$ com a cidade, tornando-as espaços funcionais, economicamente individualizados e como entes em intercâmbio.

Nesse contexto, as vilas operárias terão serventia e funções que vão além de moradias para os operários. O desenvolvimento do setor industrial necessita

6 Moreira (2011) utiliza o termo fazenda, pois o momento histórico é influenciado pelos ciclos econômicos (açúcar, algodão, café, borracha etc.). A mudança vem com a divisão territorial do trabalho, na qual a cidade passa a funcionar sob o ritmo da indústria e a fazenda também se modifica, vira campo, fornecedora de alimentos e de matérias-primas e recebedora de industrializados vindos da cidade. Não há, portanto, relação cidade-campo, pois também não havia cidade e campo no sentido econômico moderno. "Há cidade. Não há campo. Porque o que existe é a fazenda, célula de um todo rural-mercantil, um ente cosmopolita por sua relação com o luxo urbano que vem de fora e dela faz a própria matriz de uma sociedade agrária com forte assento na cultura citadina.” (MOREIRA, 2011, p. 112). 
regularizar e normatizar a vida do operário, disciplinar o tempo e o espaço dos homens e mulheres que migram tanto da fazenda quanto da cidade para a fábrica. Para tanto, a indústria

[...] necessita regulamentar a vida cotidiana desses homens e mulheres na regularidade da rotina de horários e prazos do tempo-espaço do relógio que disciplina e ordena a rotina do trabalho dentro da fábrica. O que quer dizer baixar um regulamento de obediência obrigatória que regule ao mesmo tempo o dia a dia do trabalho na fábrica e na vila operária, disciplinando homens e mulheres numa só consonância de movimentos (MOREIRA, 2011, p. 113).

A vigilância e o controle tornam-se tônicos do espaço-tempo disciplinar da vila operária. Pois, ao mesmo tempo que se fixam os operários nas imediações das instalações fabris para a constituição de um mercado de trabalho cativo, ainda os mantém sob o controle político e ideológico (BONDUKI, 1994).

Para Blay (1982 apud BONDUKI, 1994), a necessidade para a criação das vilas operárias decorre de três motivações principais: a) aspectos operacionais; b) mercado de trabalho; c) político-ideológicas.

Para a primeira motivação o argumento liga-se à importância que os trabalhadores têm para a continuidade do processo de produção (manutenção e funcionamento). A segunda motivação consiste na dificuldade para obter mão de obra qualificada ou mesmo de trabalhadores em geral devido à localização da fábrica. E a terceira motivação parte do princípio de controle que ultrapassa o espaço-tempo do trabalho na fábrica, pois, logo se associa a perda do trabalho com o despejo da casa, assim evitando as greves e paralisações (BLAY, 1982 apud BONDUKI, 1994).

A exceção, no que tange ao afastamento do Estado na produção direta de moradias, se deu de maneira específica e pontual. Logo no início do século XX, o governo federal construiu vilas operárias, tais como: a Vila Marechal Hermes e a Vila Orsina da Fonseca na cidade do Rio de Janeiro (OLIVEIRA, 2009), e houve ainda a construção de quarenta unidades em Recife pela Fundação Casa Operária (BONDUKI, 1994).

A ruptura da organização política no Brasil no ano de 1930 tem como origem fatores de cunho externo e interno. No que tange ao fator externo mais significativo destaca-se a Quebra da Bolsa de Nova York, em outubro de 1929, cujas consequências para a economia nacional foram consideráveis, uma vez que baseava-se fortemente na exportação de produtos primários, sendo o café o principal produto exportado.

Por outro lado, os fatores internos relacionavam interesses de ordem política e econômica. Destarte, dentre os estados mais fortes economicamente, o Rio 
Grande do Sul era o único que não dependia fundamentalmente dos mercados externos, pois tanto o arroz quanto o charque que produzia destinavam-se principalmente ao mercado nacional. Portanto, a depressão econômica que afetou São Paulo, Minas Gerais e Rio de Janeiro fortaleceu, ao mesmo tempo, a oligarquia gaúcha liderada por Getúlio Vargas. E ainda, a ruptura da aliança conhecida como "café com leite" por parte da elite paulista conduziu os políticos mineiros a apoiar a Revolução de 1930 (BUENO, 2010).

Em meio a todo esse contexto de agitação política, a economia apresentava sinais de crise, segundo Bueno (2010), antes do fim de 1929 já havia no país 2 milhões de desempregados, 579 fábricas foram fechadas em São Paulo e no Rio de Janeiro e o salário dos trabalhadores fora reduzido cerca de $40 \%$ a $50 \%$.

A sustentação política inicial desse novo regime contava com atores sociais que até então não participavam do poder central de maneira direta, tais como tenentes, classes médias, oligarquias periféricas. Todavia, esses atores não possuíam força suficiente para a manutenção do regime no poder do governo federal. Vargas busca legitimar o poder do novo Estado brasileiro com a incorporação das massas populares urbanas (BONDUKI, 1994).

Após 1930, segundo Bonduki (1994), o Estado brasileiro formula políticas econômicas e sociais com características bem definidas, mesmo que às vezes fossem contraditórias e descontínuas. Para o autor, o governo Vargas impulsionou uma política voltada aos trabalhadores e concomitantemente produziu uma estratégia de desenvolvimento industrial.

A expansão da atuação do Estado é acompanhada por novos processos econômicos e de organização social. Ao mesmo tempo que se consolida o padrão de acumulação urbano-industrial, também emergem as demandas das massas populares urbanas, com destaque para a habitação.

A forte crise nacional de habitação da década de 1930, apresentada por Melo (1990), Bonduki (1994) e Trompowsky (2004), é resultado de um desdobramento histórico no qual a participação do Estado no provimento das moradias era desconsiderada pelos ideais liberais que dominavam o pensamento político desde o século XIX.

Para Bonduki (1994), a intervenção do Estado na questão habitacional a partir da década de 1930 possui dupla motivação. A primeira está no sentido de ampliar a legitimidade do regime a partir do apoio das massas populares urbanas, uma vez que a crise da habitação representava um ônus considerável para a classe trabalhadora; assim, a formulação de um programa de produção de moradias e de uma política de proteção ao inquilinato lograria ampla aceitação nesse segmento social. A segunda motivação consiste na necessidade de "viabilizar uma maior acumulação de capital no setor urbano através da redução do custo de reprodução da força de trabalho" (BONDUKI, 1994, 717). 
Todavia, as motivações para a intervenção estatal na resolução da crise habitacional não culminaram de fato em uma política habitacional estruturada e harmoniosa durante a Era Vargas. Mesmo assim, é notório o papel assumido pelo Estado quanto ao problema da habitação como uma questão social.

De fato, as ações governamentais nesse período deram início à ideia de habitação social. Destacam-se durante Estado Novo (1937-1945) duas medidas que impactaram na forma de produção de habitações: a) a criação das carteiras prediais dos Institutos de Aposentadorias e Pensões (IAPs); b) a Lei do Inquilinato.

As repercussões da crise de habitação no fim da Era Vargas alcançaram o discurso político, passando a ser parte fundamental dos programas eleitorais dos candidatos à presidência. O retorno ao modelo democrático impunha ao Estado brasileiro a necessidade de respostas às demandas sociais.

O contexto do pós-guerra transformou as relações políticas no Brasil, marcado por um cenário de crise de habitação, crescimento das favelas e expansão das periferias. A atuação pontual e sem resultados contundentes na habitação popular produziu um efeito ainda mais perverso nas favelas, pois elas passaram a constituir um reduto de base eleitoral, sujeito aos interesses momentâneos.

A "Politização das Favelas", é o termo utilizado por Melo (1990), que designa o momento de "descoberta" das favelas na década de 1930 e que balizará as políticas populistas da década de 1940. O discurso político utiliza, cada vez mais, os termos "povo" e "morro" e, assim, busca cooptar as massas urbanas que crescem em um ritmo acelerado. Segundo Melo (1990, p. 42), “as favelas se convertem gradativamente num território a ser explorado, de uma parte, pelo sistema político que vislumbrava a sua incorporação problemática à arena política, e, de outra parte, pela Igreja, que estava empenhada numa política de rapprochement com o Estado".

A participação da Igreja Católica é essencial na elaboração do discurso conservador e de políticas habitacionais pontuais, com vistas principalmente à contenção do pensamento comunista nas favelas.

De acordo com Melo (1990), como a Igreja alcançava tanto as favelas quanto as instâncias de decisão, a solução mais congruente para a estabilidade social sustentava-se na propriedade privada, ou seja, na posse de um imóvel.

Conforme Trompowsky (2004) assevera, o Governo Federal aceita a proposta da Igreja Católica e cria na cidade do Rio de Janeiro a Fundação Leão XIII, cujo objetivo é atuar nas favelas para não permitir a irrupção das massas urbanas, a qual colocaria em perigo a ordem estabelecida. Cabe assinalar também que o processo de "descoberta das favelas" pelo Estado e pela Igreja se deu a partir do agravamento dos conflitos de terra urbana (MELO, 1990).

Com efeito, sobretudo na organização política de cunho conservadora e de setores da Igreja Católica, a crise de habitação durante o governo Dutra conduziu a 
política social a um consenso, incorporando as demandas dos setores sociais populares e empresariais do ramo da construção civil. A estratégia política providenciou, com rapidez, o estabelecimento de uma instituição para a construção de moradias populares, a Fundação da Casa Popular (FCP), em 1946 (MELO, 1990).

Em resumo, o período histórico que perpassa o início do século XX foi marcado por transformações marcantes na sociedade brasileira. Os estímulos estatais para a promoção do processo de industrialização permitiu a canalização de recursos (humanos e de capitais) em volumes crescentes para as cidades, principalmente, Rio de Janeiro e São Paulo. Contudo, devido à hegemonia do paradigma liberal das décadas passadas, no qual o provimento das habitações para os trabalhadores não era uma política de Estado, a carência de moradias se acentuou ao longo dos anos de 1930 e 1940 . O processo que se seguiu foi o aumento no número de favelas.

Contraditoriamente, as massas urbanas, ao mesmo tempo que eram as vítimas das práticas políticas e econômicas, serviram também de apoio à proposta populista do Governo Federal. A “descoberta” das favelas pelos poderes políticos e religiosos se deu por duas motivações principais: primeira, o crescimento das massas urbanas em áreas de favelas constituía-se em uma ameaça à estabilidade política e social, uma vez que os ideais comunistas se colocavam como alternativas aos trabalhadores pobres; segunda, a produção de discursos políticos, tal como o combate à crise da habitação, visava "tranquilizar" as massas urbanas e ao mesmo tempo servir de suporte eleitoral àqueles que estavam no controle da máquina estatal.

\section{2 À GUISA DE CONCLUSÃO}

As ações estatais no plano habitacional foram caracterizadas pela falta de compromisso com a produção direta de moradias populares durante os períodos do Brasil Império e República Velha. E ainda, as leis e decretos criados para regulamentar e estimular a produção de habitações por iniciativa privada geraram outros tipos de problemas socialmente cruéis, tais como a expulsão dos moradores pobres da área central para áreas mais distantes.

Os argumentos utilizados para as primeiras ações no âmbito habitacional durante o período Imperial eram, a princípio, com teor higienista com vistas à saúde pública, todavia, havia claramente a intenção de retirar a população mais pobre da área central e transferi-las para os arredores da cidade.

O padrão que prevalece durante a República Velha reafirma a posição do Estado como agente regulatório para a produção de moradias pelo capital privado. Tal estímulo permitiu o crescimento da produção rentista, ou seja, de habitações para aluguel. E também, com efeito ao contexto de crescimento das indústrias no 
país, surgem as vilas operárias como resposta à crise de moradias populares e, ao mesmo tempo, como necessidade de controle total sobre a vida do operário.

As consequências dessas ações estatais no plano habitacional produziram e agravaram as perversidades sociais ao longo do tempo. Desde então, o modo de enfrentamento do Estado brasileiro à questão habitacional não produziu espaços urbanos menos desiguais social e economicamente. Pelo contrário, as políticas urbanas não foram bem conduzidas, pois, criaram e reforçaram os problemas inerentes ao processo de urbanização, nos quais os custos sociais são elevadíssimos para a parcela mais pobre da população.

\section{REFERÊNCIAS}

ABREU. M. A. Da habitação ao Habitat: a questão da habitação popular no Rio de Janeiro e sua evolução. Revista Rio de Janeiro, n.10, p. 210-234, maio/ago. 2003. ARRETCHE, M. Intervenção do Estado e setor privado: o modelo brasileiro de política habitacional. Revista Espaço \& Debates, São Paulo, ano X, n. 31, p. 21-36, 1990. AZEVEDO, S. ANDRADE, L. A. G. Habitação e poder: da Fundação da Casa Popular ao Banco Nacional da Habitação. Rio de Janeiro: Centro Edelstein de Pesquisas Sociais, 2011.

BONDUKI, N. Origens da habitação social no Brasil. Análise Social, vol. XXIX, p.711732, 1994.

. Origens da habitação social no Brasil: arquitetura moderna, lei do inquilinato e difusão da casa própria. São Paulo: Estação Liberdade, 2011.

BRASIL. Decreto n ${ }^{\circ} .2 .686$, de 30 de outubro de 1875. Autoriza o Governo para conceder isenção de décima urbana ao Bacharel Américo de Castro, ou as empresas que se organizarem para a construção, nesta cidade, de edifícios denominados "Evonias". Coleção de Leis do Império do Brasil - 1875, vol. 1, parte 1, p. 186. Disponível em: <http://www2.camara.leg.br/legin/fed/decret/1824-1899/decreto-2686-30-outubro-1875549774-norma-pl.html> Acesso em: 23 fev. 2015.

BRASIL. Decreto n ${ }^{\circ}$. 3.151, de 9 de dezembro de 1882. Concede favores a Américo de Castro e as empresas que se organizarem com o fim de construir edifícios para habitação de operários e classes pobres, na cidade do Rio de Janeiro e seus arrabaldes. Coleção de Leis do Império do Brasil - 1882, vol.1, parte 1, p.150. Disponível em: <http://www2. camara.leg.br/legin/fed/decret/1824-1899/decreto-3151-9-dezembro-1882-544803norma-pl.html>. Acesso em: 23 fev. 2015.

BUENO, E. Brasil: uma história: cinco séculos de um país em construção. São Paulo: Leya, 2010.

CORREIA, T. B.; GHOUBAR, K.; MAUTNER, Y. Brasil, suas fábricas e vilas operárias. Pós. Revista do Programa de Pós-Graduação em Arquitetura e Urbanismo da FAUUSP, [S.l.], n. 20, p. 10-32, dez. 2006. Disponível em: <http://www.revistas.usp.br/posfau/ article/view/43483/47105>. Acesso em: 23 fev. 2015. 
LEFEBVRE, H. O direito à cidade. Tradução, prefácio e notas Rubens Eduardo Frias. São Paulo: Centauro, 2001.

State, space, world: selected essays / Henri Lefebvre; edited by Neil Brenner and Stuart Elden; translated by Gerald Moore, Neil Brenner, and Stuart Elden. Minneapolis: University of Minnesota Press, 2009.

MELO. M. A. B. C. Política de habitação e populismo: o caso da Fundação da Casa Popular. Revista de Urbanismo e Arquitetura, vol. 3, n. 1, p. 39-61, 1990.

MOREIRA, R. Sociedade e espaço geográfico no Brasil. São Paulo: Contexto, 2011. OLIVEIRA, A. C. T. O bairro de Marechal Hermes: da moradia operária à habitação social (1910-1956). 2009. 159 f. Tese - Universidade Federal Fluminense, Niterói, 2009. PRADO JÚNIOR, C. História econômica do Brasil. São Paulo: Brasiliense, 1998. SANTOS, M. A urbanização brasileira. São Paulo: Editora da Universidade de São Paulo, 2009.

. Ensaios sobre a urbanização latino-americana. São Paulo: Editora da Universidade de São Paulo, 2010.

Pobreza urbana. 3.ed. São Paulo: Editora da Universidade de São Paulo, 2013. SINGER, P. Economia política da urbanização. São Paulo: Brasiliense, 1973.

TROMPOWSKY. M. A FCP - Fundação da Casa Popular e a implantação de uma política habitacional no Brasil: o processo de uma experiência governamental no campo da habitação popular. Seminário de História da Cidade e do Urbanismo, Rio de Janeiro, v. 8, n. 4, p. 1-17, 2004.

VAINER, C. B. Os liberais também fazem planejamento urbano? In: ARANTES, O. et al. A cidade do pensamento único: desmanchando consensos. Petrópolis: Vozes, p. 105119, 2000.

VERAS, M. P. B.; BONDUKI, N. G. Política habitacional e a luta pelo direito à habitação. In: COVRE, M. L. M. (Org.). A cidadania que não temos. São Paulo: Brasiliense, 1986.

VILLAÇA, F. Espaço intraurbano no Brasil. São Paulo: Studio Nobel/FAPESP, 2001. . Reflexões sobre as cidades brasileiras. São Paulo: Studio Nobel, 2012. 